\title{
The hospitalisation of death: should more people die at home?
}

\author{
Ann Bowling Department of Clinical Epidemiology, The London Hospital Medical College
}

\begin{abstract}
Author's abstract
With the increase in the proportion of hospital deaths there is increasing debate about appropriateness of place of death. Death should be a family affair but is increasingly hidden from public view. In contrast to those who die at home, most of those who die in hospital die alone with no relatives or friends with them. Husbands and wives are less likely to have the opportunity to say 'goodbye' to their dying spouses. As people become less familiar with death they may increasingly assume that the terminally ill are better cared for in hospital. However, this need not be the case. Most people want to die at home, most do not for social rather than medical reasons. It is not the illness itself which leads to hospital admission in many cases but its duration and nature - and the type of burden it places on relatives. Although home care should be encouraged where possible, no amount of exhortation to the family or to the dying person of the advantages of home care can disguise the fact that demand for domiciliary services is greater than is now being provided. The paper is based on one read to a London Medical Group Symposium.
\end{abstract}

Death like birth, is a family affair, but hospitals are increasingly the site of both. Just as there is a debate about home versus hospital confinements in the case of childbirth, so there is an increasing feeling that the hospital is frequently an inappropriate place in which to die. It appears unkind in the case of an expected death to remove a person from the familiarity of a home environment during the last days of life. Inevitably, in some cases hospital facilities may be needed. In many cases, however, it appears that terminal care takes place in hospital for social reasons.

In 1966, 54 per cent of deaths occurred in hospitals or other institutions for the care of the sick. A decade later this proportion had risen to 60 per cent. In urban areas the proportion of hospital deaths is even higher at 70 per cent $(1,2,3)$. As Western culture has sought to gain control over nature so it has sought to control death. Doctors have been given responsibility for

\section{Key words}

Dying; death; terminal illness; medical ethics; hospital care; home care; grief. combating it and death has increasingly become a 'medical problem' instead of a natural event. Illich (4) in his book Medical Nemesis said:

'Today the man best protected AGAINST setting the stage for his own dying is the sick person in critical condition. Society, acting through the medical system, decides when and after what indignities and mutilations he shall die.'

Such statements ignore the benefits of medical care in certain life-threatening situations but emphasise the impotence individuals may feel in the face of their own deaths. The decision to die at home, where home care is possible, may enable one to feel, in contrast, that choice is being exercised and that some control has been retained. People have a right to die with dignity to die in their own way, be it at home or elsewhere. The advantage of dying at home means, however, that people may be able to influence the quality of their lives - assuming adequate support is available.

Hospitals are anxiety-provoking places for patients and research has shown that hospital staff withdraw from the terminally ill at the very time they are needed - as death approaches. Nurses take longer to respond to the calls of terminally ill hospital patients than to those of the less severely ill and doctors also appear to cope with death by avoiding patients once they have begun to die (5). Although the fault here lies in medical education there may still not be the privacy or psychological preparation necessary for terminal care in acute hospitals. On the other hand, those dying in such hospitals arguably have access to a number of life-prolonging or palliative treatments. But most people who do not die at home do not die in high-technology teaching hospitals but in hospitals and institutions for the chronic sick. The advocates of hospice care and community terminal care support units would also probably argue that they could provide necessary facilities and treatments for people dying at home, as well as the assurance of a bed in a hospital or hospice should circumstances necessitate it.

Because of the increase in the proportion of hospital deaths the public are less likely than previously to witness death. In a recent national survey of death and bereavement among the elderly - in which just 4 per 
cent of the deaths were sudden with no previous condition or illness - it was found that 74 per cent of people who died in a hospital died alone with no relatives or friends with them as opposed to 15 per cent of those who died at home (6). These are similar to the proportions found in an earlier survey of deaths among all age groups (7). In the former study, the widowed people were interviewed on average five months after the death of the spouse. It emerged that even when the widowed stayed overnight at the hospital to be with their husband or wife they were often absent at the time of death. As one widow interviewed said:

'I had been there (in hospital) for eight or nine days, I hardly left his side. The day he died I'd had the opportunity to come home for a couple of hours as I was feeling the strain, and two hours after I left he died.'

This also has implications for adjustment to bereavement for those left behind. The surviving widowed people who were not present at the deaths of their spouses were asked whether they would have preferred to have been with their husband or wife then. Over half, 59 per cent, said they would. Being with the person at the time of death to say 'goodbye' may lessen feelings of guilt or anxiety among the bereaved. Two people in the sample said:

'I'd like to know what happened - a chance to say "Bye bye" and "Thanks for what you've done". I'd like to know if he called out or suffered before he went.'

'(I'd lost the last) chance I had to see my husband. This is why I can't sleep. I don't know if he went in agony - if he asked for me-I know nothing . . . I feel very bitter.'

As people become less familiar with death so they may increasingly assume that the terminally ill are better cared for in hospital. However, this need not be the case as in a recent study comparing a reputable hospital and a hospice, and in- and out-patient care, no consistent differences were found in the quality of terminal care provided (8). The only differences found were that people were least depressed and anxious at a hospice and preferred the more frank communication about their condition available there. Also, in-patients were slightly less mentally troubled than out-patients. Patients actually gave most praise to the out-patients system of care despite experiencing a little more anxiety or irritability at home. But treatment cannot be judged solely by the mental quiet it brings. As the author pointed out: the familiarity and freedom of a home environment may be preferred even if anxiety is increased.

Kalish and Reynolds (9) in their survey of terminal care found that most people said they would prefer to die at home and their relatives also tended to prefer this. In the survey of terminal care and bereavement among the elderly, previously referred to (6), the widowed whose spouses had died at home were asked whether they would rather the person had been in hospital or whether they were glad he or she had died at home. The majority, 91 per cent, said they were glad their spouse had been at home when he or she died. The indignities sometimes suffered by those dying in hospital are illustrated in the following widow's statement:

'When they get you into hospital they make you sit in a chair for hours, then you progress to a wheelchair and from there to an infection and that's it. Old people should never be allowed to die like that. They should be kept within the family unit.'

Home deaths were generally preferred among these people even when considerable burdens had been placed upon them. One widow said:

'I couldn't go far. I couldn't go anywhere - just down the road shopping. I couldn't leave him for any length of time. It made me confused and ill at times - looking after him for so long. For the past few months I had to carry him to the bathroom.'

However, these carers generally accepted the burden of caring that had been placed upon them as their duty:

'It was like living in a vacuum really, it was all unreal, but I would not have had it any other way.'

The burden was also considerable for those whose spouses died in hospital as few were in hospital for long. In fact, just 8 per cent of all the people who died in this sample were in hospital for three months or more during their last year of life. However, care of the dying still forms a sizeable part of the hospital's workload. Cartwright $e t$ al calculated that more than a quarter of hospital bed days are taken up by people who will be dead within a year (7).

The widowed whose spouses died in hospital were asked, in the study previously quoted (6), whether, if adequate nursing and other help had been available, it would have been possible for the deceased to have been looked after at home. The majority, however, 82 per cent, said 'no'. The main reason given, by four-fifths of these, was that hospital facilities were needed. This brings us back to the point that, as most deaths take place in hospital, people probably have a low opinion of home care facilities for the terminally ill. In some cases, this may be reinforced by the poor quality and quantity of such facilities. In order to examine fully the issue of whether more people should die at home some analysis of who dies in hospital and of the usual indications for admission is necessary.

\section{Who dies in hospital?}

Surveys have found that those people most likely to die in hospital are the unmarried, wives rather than husbands, those who have been ill for between three 
months and two years rather than two years or more, those aged under 45, and those without children, particularly daughters, available to care for them. Clearly, most caring takes place at home and it is those without relatives able to care for them who tend to die in hospitals or institutions $(6,7)$.

National statistics show that people dying of cancer, stroke, respiratory disease and from relatively uncommon diseases are more likely to die in hospital than those dying from other conditions (2). Cartwright et al (7) found that those dying in hospital were more likely to have suffered from pain and mental confusion. Those dying at home were less disabled in terms of their ability for self care. Incontinence was no more frequent among those dying in hospital than at home but those dying in hospital had been incontinent for longer. Research has shown that relatives have most difficulties tolerating incontinence, personality disturbances and difficulties walking and getting out of bed unaided (10).

\section{Indications for admission}

Terminally ill people are often admitted to hospital in the final stages of their illnesses for social reasons, namely the lack of adequate care available in the community. A recent study of indications for admission in the last week of life supports this (11). It was not the illness itself which had the greatest influence on the possibilities for home care, but the duration and nature of the illness - the way in which the illness was manifested in terms of pain, confinement to bed, no longer being able to eat and drink independently, and incontinence. A patient who is confined to bed and completely dependent on others requires constant care, including care at night. This can be a heavy physical task. Relatives in this study who saw the possibilities for home care as limited referred to this physical burden and to the consequences for their own daily routine and life. Lack of adequate medical help and support was also cited as a factor discouraging home care. Those relatives who felt care at home was difficult also mentioned fear of sole responsibility for the patient, fear of unexpected situations, the need for accessible emergency help, not knowing what is happening or where to turn. These are fears which could, of course, be allayed by a good domiciliary terminal care support team.

As most studies involving interviews with the terminally ill find that most express a preference for the death to take place at home, then, arguably, this wish should, where possible, be respected $(9,12)$. However, if the dying person does not obtain adequate care at home then home care is less justifiable - although it is the inadequate caring services which must be questioned. It is sometimes believed that relatives shirk their responsibilities when it comes to caring for the sick and elderly. Thirty-eight per cent of the widoweds' GPs questioned in a survey of terminal care and bereavement certainly believed this (6). However, little evidence was found to support this belief in that study.
Other researchers have estimated that the unreasonable refusal of relatives to care for dying family members occurs in only about 1 per cent of terminal cases $(13,14)$. The family is an important source of care and support. Inescapably, most help is given by the family, not by professionals. In reality it is not that the sick or old are helped by doctors, doctors by nurses and nurses by families but the other way round. Professionals, when involved, simply perform marginal tasks and leave the major carer (the relative) to provide frontline, 24-hour care. This care is not without some degree of strain, as previously indicated, and the advantages of home care need to be weighed against this. Isaacs (14) found that a major reason for geriatric admissions was that relatives were suffering undue strain from their caring role. A quarter of the elderly widowed in the earlier study quoted on death and bereavement (6) said their normal activities were severely restricted, a fifth said they were fairly restricted and a further fifth said they were a little restricted because of the care they gave to the deceased. Some of these carers were not only receiving inadequate help themselves but were also frail. In fact, 30 per cent were frailer or as frail as the person who died. One widow said:

'I was an ill person over 80 with a heart complaint and yet they sent a dying man home to me with no help at all. I had a bed downstairs for him but he was always messing it. He had no control over his legs. When he fell I had a 12-stone man to lift - and I've got a heart condition! I was so tired my ankles were enormous at night. I had to sleep in the chair in the end as I was too tired to go up and down stairs.'

\section{Another widow said:}

'He had primary cancer in his stomach and spleen - he had them removed but it had gone too far. The doctors gave him two months but I kept him alive by nursing him for 18 months, and they sent me no nursing help at all.'

While the spouse bore the brunt of caring for the dying person, relatives and friends also helped in many cases. However, a fifth of the widowed felt that more help was needed in caring for the personal needs of the deceased. Again, in one large-scale survey of cancer patients dying at home, it was found that general practitioners felt local facilities to be deficient in more than half the areas studied. This may explain why patients dying at home have been found to need more help than they are getting $(15,16)$. Nearly a quarter of the national sample who died in Cartwright et al's study (7) were felt by relatives to have needed more help from a district nurse and 57 per cent from a home help. A third of patients' general practitioners questioned in the study said that inadequate supporting services, other than district nursing services, prevented more people being looked after in the community rather than in hospital. However, 14 per cent of the district nurses providing 
care also said that GPs did not refer patients to them early enough. No amount of exhortation to the family ir to the dying person of the advantages of home care can disguise the fact that the demand for domiciliary services is greater than is now being provided. On the other hand, not all carers are aware of how to obtain help or better facilities to care for the dying person at home. They may never ask for help or they may ask the wrong person. Cartwright et al (7) found a number of symptoms being suffered from by the deceased over which no advice from professionals had been sought. Lack of advice-seeking may in some cases have been a realistic assessment of help available. Not only had there been no consultation about a number of distressing symptoms but even where there had been consultation, in many cases relief had not been obtained.

A final implication for adjustment to bereavement should be mentioned. In the study of the elderly widowed referred to, it was found that the feeling among the widowed that they were left to look after their dying spouse alone, without adequate support, clearly contributed to a wish that things had been done differently before the death. This, in turn led to a poorer emotional adjustment after the death. In $38 \mathrm{per}$ cent of instances where the deceased needed care, the widowed person had provided it entirely alone. In a further 39 per cent they were the main carers. So, although home care may sometimes alleviate relatives' feelings of personal guilt, guilt and anger directed against professionals may be increased if professional support is inadequate.

\section{Conclusion}

So should more people die at home? Cartwright et al (7) found that about half their national sample of patients' general practitioners said if they had more time it would be appropriate for them to look after more terminally ill patients at home. Just two-fifths said they would like to give more time to these patients. Nearly two-thirds of the district nurses questioned said they would like to give more time to the terminally ill. But this leaves most, three-fifths, of the doctors and a third of the district nurses not wishing to give more time to the care of the terminally ill at home.

The answer to the question is only a qualified yes. Home care may be regarded as appropriate if the patient wants to die at home; if community support and professional services are available; and, of course, if hospital facilities are not needed. There are advantages in dying at home which should be emphasised:

a) Home deaths are more natural.

b) The dying person may have more opportunity to influence the quality of his or her life.

c) The dying person may feel more wanted if not rejected by the family and/or community.

d) A home environment provides psychological comfort by virtue of its familiarity. e) The guilt of the bereaved due to typical feelings of 'Perhaps I should have done more' may be alleviated if they provide the care - but only if adequate support is given.

Finally, I would like to point out that the subject of this debate begs one very important question - it assumes that the patient is in a position, by virtue of being fully informed about his or her condition, to choose where to die. In fact, the patient is usually the last person to be informed, if he or she is informed at all. Although patients are believed to know intuitively when they are going to die (8), doctors tend to inform relatives of the prognosis rather than the person actually dying $(6,7)$.

\section{Acknowledgment}

I am indebted to Dr Ann Cartwright, joint author of Life after death: a study of the elderly widowed who has also given valuable support and advice. I am grateful to her and to other colleagues and advisers at The Institute for Social Studies in Medical Care where the study was carried out.

\section{References}

(1) General Register Office. The Registrar General's statistical review of England and Wales for the year 1966. Part 1, tables medical. London: HMSO, 1967.

(2) Office of Population Censuses and Surveys. Mortality statistics 1977. London: HMSO, 1979.

(3) Ahmedzai S. Dying in hospital: the residents' viewpoint. British medical journal 1982; 285: 712-714.

(4) Illich I. Medical nemesis. London: Calder-Boyars, 1976.

(5) Schultz R, Aderman D. How medical staff cope with dying patients. A critical review. In: Kalish $R$, ed. Caring relationships: the dying and the bereaved. New York: Baywood, 1977.

(6) Bowling A, Cartwright A. Life after death: a study of the elderly widowed. London: Tavistock, 1982.

(7) Cartwright A, Anderson J, Hockey L. Life before death. London: Routledge and Kegan Paul, 1973.

(8) Hinton J. Whom do dying patients tell? British medical journal 1980; 281: 1328-1330.

(9) Kalish R, Reynolds D. Death and ethnicity: a psychocultural study. Los Angeles: University of Southern California Press, 1976.

(10) Sanford J R A. Tolerance of debility by supporters at home. In: Carver V, Liddiard P. An ageing population. London: Hodder and Stoughton, Open University Press, 1978.

(11) Gennip-Horsten van T. Ambulant terminal care: an addition or an alternative? In: Pegg P, Metze E. Death and dying: a quality of life. London: Pitman, 1981.

(12) Kalish R. Death and dying in a social context. In: Binstock R, Shanas E. Handbook of ageing and the social sciences. New York: Van Nostrand Reinhold, 1976.

(13) Lowther C P, Williamson J. Old people and their relatives. Lancet 1966; 2: 1459.

(14) Isaacs B. Geriatric patients - do their families care? British medical joumal 1971; 4: 282.

(15) Hughes H. Peace at last. London: Calouste Gulbenkian Foundation, 1960.

(16) Hinton J. Dying. Harmondsworth: Penguin Books, 1972. 